\title{
Mechanically Induced Fracture Face Skin - Insights from Laboratory Testing and Modeling Approaches
}

Andreas Reinicke, SPE, Guido Blöcher, Günter Zimmermann, Ernst Huenges, Georg Dresen, GFZ German Research Centre for Geosciences; Sergei Stanchits, TerraTek; Björn Legarth, SPE, and Axel Makurat, Royal Dutch Shell

\begin{abstract}
In context of this work, a new formation damage mechanism is proposed: the mechanically induced fracture face skin (FFS). This new mechanism results from mechanical interactions between the proppants and the reservoir rock, due to the increasing stress on the rock-proppant system during production. Proppant embedment into the fracture face and proppant crushing leads to fines production and may impair the fracture performance. In order to achieve sustainable, long-term productivity from a reservoir, it is indispensable to understand the hydraulic and mechanical interactions in rock-proppant systems. Permeability measurements on sandstones with propped fractures under stress using different flow cells were performed, allowing localizing and quantifying the mechanical damage at the fracture face. The laboratory experiments identified a permeability reduction at the fracture face up to $90 \%$. The mechanical damage at the rock-proppant interface begins immediately with loading the rock-proppant system and for fracture closure stresses below $35 \mathrm{MPa}$; the damage is localized at the fracture face. Microstructure analysis identified quartz grain crushing, fines production and pore space blocking at the fracture face causing the observed mechanically induced FFS. At higher stresses, damage and embedment of the ceramic proppants further reduces the fracture permeability. Numerical modeling of the rock-proppant system identified highly inhomogeneous stress distributions in the granular system of grains and proppants. High tensile stress concentrations beneath the area of contact between quartz grains and proppants are observed even at small differential stress applied to the rock-proppant system. These high stress concentrations are responsible for the early onset of damage at the fracture face. Therefore, even low differential stresses, which are expected under insitu conditions, may affect the productivity of a hydraulically fractured well.
\end{abstract}




\section{Introduction}

Design of an appropriate fracture geometry as well as placement of a sufficient proppant pack of the right proppant type is a key parameter to maintain long-term productivity. Proppant selection must consider appropriate hydraulic conductivity at in-situ stress conditions. Hydraulic conductivity is influenced by mechanical stress on proppant pack and rock-proppant interface, leading to proppant crushing and embedment as well as to a reduction of fracture width and fines production (Anderson et al., 1989). The production analysis often indicates a post-fracture well productivity that is significantly lower than expected from fracture characteristics simulations (Cramer, 2005, Romero et al., 2003). Hence, there is still a need for better understanding and investigating the complex mechanisms influencing the permeability alteration of rockproppant systems.

Treatment failure can be commonly attributed to fracture damage processes, such as: poor clean-up after the treatment, alterations due to infiltration processes and precipitation, and mechanical damages like proppant pack failure (Economides and Nolte, 2000). A wide range of laboratory, field, and theoretical studies cover the aspects of fracture damage mechanisms (Fredd et al., 2000; Wen et al., 2006; Behr et al., 2002; Nasr-El-Din, 2003; Moghadasi et al., 2002; Lynn et al., 1998). Cinco-Ley \& Samaniego V. (1977) introduced a potential fracture damage mechanism, the so-called fracture face skin (FFS), which describes a fluid flow impairment along the fracture face. The FFS is a function of fracture length, reduced permeability and extent of damaged zone adjacent to the fracture face (Fig. 1). A FFS can be caused by a variety of effects like fluid-loss damage (CincoLey and Samamiego-V., 1981), filter cake build-up at the fracture face (Romero et al., 2003), water blockage (Holditch, 1979) as well as liquid condensate (Wang et al., 2000).

Although there exists the mentioned fracture face skin models, mechanical effects have yet not been taken into account. We expect that the mechanically induced fracture face skin results from interaction between proppants and rock grains.

With increasing differential stress on the rock-proppant interface, proppants get embedded into the rock matrix and grains get crushed (Fig. 2). This leads to fines production, pore blocking and a compacted zone at the fracture face with a reduced permeability. Figure 2 exemplifies the formation of the mechanically induced FFS.

In order to describe this permeability reduction at the fracture face, three different permeabilities within the rockproppant system have to be taken into account: 1) rock permeability, 2) FFS permeability and 3) fracture (proppant pack) permeability. For that purpose, a cylindrical element of the fracture wall with the adjacent proppant pack is tested experimentally with two different flow cells: The Acoustic Emission Flow Cell (AEFC) 
and the BiDirectional Flow Cell (BDFC). The AEFC is employed for localization of the crushing events at the rock-proppant system and the BDFC simulates the geometric flow conditions in reservoirs intersected by a proppant filled fracture and is used to quantify the permeability reduction at the fracture face (Fig. 3).

The stresses in rock-proppant systems are studied by means of an analytical and a numerical stress modeling approach to understand the destruction of proppants and rock grains. The analytical approach employs the theory of diametral point loading of a sphere and adopts this concept to the contacts at the rock-proppant interface. The numerical approach transfers the contact geometry from a thin section to a finite element modeling software. The arising stresses are computed from a numerical simulation of a rock-proppant interaction experiment. The observed fracture patterns in proppant filled fractures can be explained from the computed stress distributions and mitigation strategies can be derived.

\section{Tested Materials}

The experiments were conducted with two types of sandstones. The first one, the Bentheim sandstone (Lower Saxony, Germany) was a Lower Cretaceous, homogeneous, yellow sandstone containing 95\% quartz, 3\% feldspar, and $2 \%$ kaolinite (Klein \& Reuschlè, 2003). The porosity was about $22 \%$ and the permeability between 1-3 D. The second rock type, the Flechtingen sandstone (Saxony, Germany) was a Lower Permian (Rotliegend) sandstone with a porosity about $10 \%$ and a permeability between $100-200 \mu \mathrm{D}$. The sandstone contained $65 \%$ quartz, 13\% feldspar, 9\% illite and 4\% carbonates (Trautwein, 2005). Two kinds of proppants were used in this study: 1) intermediate strength proppants (ISP), designed for a maximum fracture closure stress of $\sim 70 \mathrm{MPa}$ and made from fused ceramics with 20/40 mesh size (proppant particle diameter: $0.4-0.8 \mathrm{~mm}$ ) with a mean diameter of about $760 \mu \mathrm{m}$. 2) High strength proppants (HSP) composed of sintered bauxite with 20/40 mesh and a mean diameter is about $700 \mu \mathrm{m}$. They were designed for a maximum fracture closure stress of $\sim 100 \mathrm{MPa}$. In total 5 experiments were conducted; testing parameters are given in Table 1.

\section{Flow Cells and Experimental Procedures}

For rock-proppant interaction testing the Acoustic Emission Flow Cell (AEFC) was equipped with 10 piezoelectric P-wave transducers (PZT) each with a resonant frequency of $1 \mathrm{MHz}$, which are glued directly in brass housings to the sample to localize the AE events and to measure elastic speed wave velocity periodically

(Fig. 3). Two additional P-wave sensors were installed in the axial direction. Software, developed at GFZ German Research Centre for Geoscience, Germany, was used for automatic picking of first motion amplitudes and for automated AE hypocenter location. First motion polarities were applied to discriminate AE source types in tensile, shear, and collapse (T-, S-, C-) events (Zang et al., 1998). AE hypocenter location error is estimated to 
be about $2.5 \mathrm{~mm}$. The BDFC setup provides two flow directions, normal and parallel to the fracture face, which allows the permeability of both the overall rock (including proppant pack) and of the proppant pack itself to be determined (Fig. 3). This flow cell simulated the geometric flow conditions in a hydraulically fractured reservoir. A stiff $\left(0.72 \cdot 10^{9} \mathrm{Nm}^{-1}\right)$ servo-controlled loading frame (MTS, Material Test Systems Corporation, Minneapolis MI, USA) was used to apply axial load, measured with a high accuracy $1000 \mathrm{kN}$ load cell (sensitivity $\pm 1 \mathrm{kN}$ ). For AEFC experiments the confining pressure was servo-controlled with an accuracy of about $0.1 \mathrm{MPa}$. The BDFC was designed to work with a manually driven Hoek Cell (Hoek and Franklin, 1968) for application of confining pressure; the accuracy is about $1 \mathrm{MPa}$. A set of Quisix plunger pumps provided a constant flow rate from top to bottom of the sample. Permeability was determined with a high resolution differential pressure transducer (Honeywell/Sensotec TJE BD121BN) with a pressure range of 3 bars and a full span error of $0.1 \%$. The deformation rate was $1 \mu \mathrm{m} / \mathrm{min}$. A constant confining pressure $\sigma_{3}=10 \mathrm{MPa}$ was applied and the sample was axially loaded $\left(\sigma_{1}\right)$ up to $60 \mathrm{MPa}$. Experiments were executed at ambient and drained conditions. The setup was downstream open against atmosphere; the mean pore pressure was about 1 or 2 bar for Bentheim or Flechtingen sandstone, respectively. Flow rate for testing the rock and the rock-proppant system was $5 \mathrm{ml} / \mathrm{min}$ for Bentheim and $0.05 \mathrm{ml} / \mathrm{min}$ for Flechtingen rock (Tab. 1). The axial strain was measured by a linear variable displacement transducer (LVDT) mounted at the end of the piston and corrected for the effective stiffness of the loading frame.

A complete test takes place in a 3 steps procedure: 1) The initial permeability of the sandstone sample, the poroelastic permeability dependence of the permeability and the Young's modulus are determined. 2) A tensile fracture comparable to an idealized hydraulic fracture generation is created, splitting the specimen perpendicular to the core axis. 3) A copper foil sealing is fitted around the fracture, the fracture is filled with $2 \mathrm{lb} / \mathrm{ft}^{2}$ $\left(\sim 10 \mathrm{~kg} / \mathrm{m}^{2}\right)$ of proppants. The specimen is mounted in the testing rig and loading up to a differential stress of 50 MPa. Differential stress is calculated according to

$$
\sigma_{\text {diff }}=\sigma_{1}-\sigma_{3}
$$

Loading is stopped in displacement mode at defined stress levels $\left(\sigma_{\text {diff }}=5,20,35,50 \mathrm{MPa}\right)$ and pore pressure drop $\Delta \mathrm{P}_{\mathrm{P}}$ at constant flow rate $\mathrm{Q}$ is measured. Permeability $\mathrm{k}$ is calculated according to Darcy's law (Darcy, 1856):

$$
\mathrm{k}=\frac{\mathrm{Q} \cdot 1 \cdot \eta}{\Delta \mathrm{P}_{\mathrm{P}} \cdot \mathrm{A}}
$$


where 1 is the sample length, $\eta$ is the dynamic viscosity of the flow medium, and $A$ is the cross sectional area of the sample. The common unit for permeability is Darcy (D), which corresponds to $0.986910^{-12} \mathrm{~m}^{2}$.

The permeability of the FFS zone $\left(\mathrm{k}_{\mathrm{S}}\right)$ can be determined from the rock permeability $\left(\mathrm{k}_{\mathrm{i}}\right)$, the proppant pack permeability $\left(\mathrm{k}_{\mathrm{f}}\right)$ as well as the overall permeability of the rock-proppant system $\left(\mathrm{k}_{\mathrm{T}}\right)$. For that purpose the setup is approximated as a series connection of hydraulic resistors $R_{i}, R_{S}$ and $R_{f}$ (Fig. 3) resulting in following equation for the FFS zone permeability:

$$
\mathrm{k}_{\mathrm{S}}=\frac{\mathrm{k}_{\mathrm{T}} \mathrm{k}_{\mathrm{f}} \mathrm{k}_{\mathrm{i}} \mathrm{w}_{\mathrm{S}}}{\mathrm{k}_{\mathrm{i}} \mathrm{k}_{\mathrm{f}} \mathrm{L}_{\mathrm{T}}-\mathrm{k}_{\mathrm{T}}\left(\mathrm{k}_{\mathrm{f}} \mathrm{L}_{\mathrm{i}}+\mathrm{k}_{\mathrm{i}} \mathrm{w}_{\mathrm{f}}\right)}
$$

where $L_{T}$ is the length of the whole specimen, $L_{i}$ is the length of the rock halves, $w_{f}$ is the width of the proppant pack and $\mathrm{w}_{\mathrm{s}}$ is the damage penetration (Fig. 3).

\section{Experimental Results: Permeability Alteration of the Rock-Proppant System}

Experiment no. 1 using Bentheim sandstone and ISP was conducted with the AEFC. Figure 4 shows the AE hypocenter locations and permeability data. AE hypocenters of 5 loading steps are projected normal to the z- and the $\mathrm{x}$-axis. In the first loading step confinement was applied. The inner part of the specimen is plotted from 40 to $80 \mathrm{~mm}$. The AE events are separated in tensile, shear and compaction type (C-, S-, T-type), plotted in green, blue, and red.

The initial rock permeability $\mathrm{k}_{\mathrm{i}}\left(\sigma_{\mathrm{diff}}=0 \mathrm{MPa}\right)$ is about $1630 \mathrm{mD}$ and shows only small variation (with respect to the error) up to maximum differential stress. At initial isostatic stress conditions, the rock-proppant system permeability $\mathrm{k}_{\mathrm{T}}$ is reduced by a factor of 4 to $374 \mathrm{mD}$. At maximum $\sigma_{\mathrm{diff}}=50 \mathrm{MPa}$, a further reduction of permeability to $300 \mathrm{mD}$ is observed.

The clustering of AE hypocenters in figure 4a indicates that grain crushing and proppant embedment starts at the fracture faces at low external stress. No crushing events within the proppant pack can be observed at small differential stress. With increasing $\sigma_{\text {diff }}$ (Fig. 4b-e) the AE activity increases and moves from the fracture face

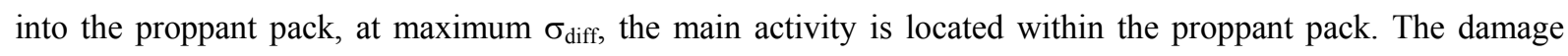
penetration $\mathrm{w}_{\mathrm{S}}$ is estimated from the thickness of AE cluster; it is about $4 \mathrm{~mm}$. With increasing stress, the proportion of T-type and S-type events increase and the proportion of C-type events decrease.

Four experiments were conducted with the BDFC. ISP and HSP type were tested with both rock types. Figure 5a-d shows the permeability alterations of the intact rock $\left(\mathrm{k}_{\mathrm{i}}\right)$, the rock-proppant system $\left(\mathrm{k}_{\mathrm{T}}\right)$, and the fracture face skin zone $\left(\mathrm{k}_{\mathrm{S}}\right)$ and as function of $\sigma_{\text {diff. }}$ A small axial load was applied in order to measure the initial 
permeability of a rock-proppant system. Hence, $\sigma_{\text {diff }}$ was negative at the beginning of an experiment $\left(\sigma_{3}>\sigma_{1} /\right.$ see equation 1).

The initial permeability $\left(\mathrm{k}_{\mathrm{i}}\right)$ of both Bentheim sandstones specimens was about $1470 \mathrm{mD}$ with no poroelastic permeability change within the loading range (Fig. 5a). Already at $\sigma_{\text {diff }}=6 \mathrm{MPa}$, the permeability of the rockproppant system $\left(\mathrm{k}_{\mathrm{T}}\right)$ showed a clear reduction compared to $\mathrm{k}_{\mathrm{i}}\left(\mathrm{k}_{\mathrm{T}}=1130 \mathrm{mD}\right.$ (ISP) $/ \mathrm{k}_{\mathrm{T}}=1090 \mathrm{mD}$ (HSP). A further reduction at maximum $\sigma_{\text {diff }}$ to $950 \pm 40 \mathrm{mD}$ and $890 \pm 30 \mathrm{mD}$, respectively, was observed. After unloading the specimen (last values in Fig. 5a), the permeability was reduced permanently and no permeability recovery can be detected. The permeabilities of the FFS zone $\left(\mathrm{k}_{\mathrm{s}}\right)$ were calculated by means of equation 3 . The ISP and the HSP specimens had a $\mathrm{k}_{\mathrm{S}}$ about $200 \mathrm{mD}$, initially (Fig. 5b). At $\sigma_{\text {diff }}=51 \mathrm{MPa}$ the specimens showed a reduced permeability by a factor of 10 and 11 (141 mD (ISP) / $120 \mathrm{mD}$ (HSP)) compared to $\mathrm{k}_{\mathrm{i}}$.

The initial permeability of the Rotliegend sandstone specimen was about $195 \mu \mathrm{D}$ with a poroelastic permeability change of about $15 \%$ (Fig. 5c). Already at $\sigma_{\text {diff }}=5 \mathrm{MPa}$, the permeability at the rock-proppant interface was reduced by a factor of $4\left(\mathrm{k}_{\mathrm{S}}=46 \mu \mathrm{D}\right.$ (ISP)) and a factor of $6\left(\mathrm{k}_{\mathrm{S}}=31 \mu \mathrm{D}\right.$ (HSP)), respectively (Fig. $\left.5 \mathrm{~d}\right)$. With increasing $\sigma_{\text {diff }}$ the permeability reduction increased and reached a factor of 6.3 for ISP $\left(k_{S}=31 \mu D\right)$. For HSP the permeability reduction at the rock-proppant interface is higher; a reduction factor of $7.8\left(\mathrm{k}_{\mathrm{S}}=25 \mu \mathrm{D}\right)$ was measured.

\section{Stress Calculation: Diametral Loading of Spheres}

An analytical approach of Hiramatsu and Oka (1966) was employed to analyze the mechanical interaction of rock grains and proppants. For that purpose, the particles in contact were approximated as isotropic elastic spheres and a simple cubic packing of spheres was assumed. The approach Hiramatsu and Oka (1966) characterize the complete stress field within a sphere under uniaxial compression (diametral load) and calculate the stresses in spheres as function of contact angle $\Theta$ and Poisson ratio $v$ of the materials.

In order to discuss the potential failure mechanisms in a diametral loaded sphere, the stress distribution $(\sigma)$ in a sphere is expressed as stress severity. The stress severity (S) describes the local stress in a sphere as a factor of the medium stress applied to the cross-sectional area of the sphere.

$$
\mathrm{S}=\frac{\sigma}{\mathrm{F} /\left(\pi \mathrm{R}^{2}\right)}
$$

where $\mathrm{F}$ and $\mathrm{R}$ are the force acting on a sphere and the sphere radius, respectively. The problem is symmetric; hence, for one quadrant of the sphere $\mathrm{S}$ was calculated using a commercially available software package. The 
maximum and minimum principle stress severity is plotted in figure $6 \mathrm{a}$ and $6 \mathrm{~b}$. Compressive stresses are plotted as positive and tensile stresses are plotted as negative here, following the usual sign conventions of rock mechanics.

Cracks propagate if the local stress in the vicinity of a material failure is high enough to meet the fracture criterion. In isotropic materials, cleavage cracks propagate perpendicular to the maximum tensile stress and shear cracks parallel to the maximum shear stress. Hence, the considerations here about breakage and fracture propagation are based on the stress field. If a local maximum of tensile stress exists, a cleavage crack can propagate from this initiation point. The stress analysis shows a possible crack pattern in the spheres as long as the cracks do not modify the stress field. Indeed, a crack modifies the stress field by definition.

Figures 6a shows that the principle stresses along the axis of loading are compressive beneath the contact area. In a small volume below the contact $(0.9<\mathrm{y}<1.0$ / Fig. $6 \mathrm{a})$, the maximum principle stress $\left(\sigma_{1}\right)$ reaches a stress severity value between 100 and 500 . The minimum principle stresses $\left(\sigma_{3}\right)$ shows localized minimum of stress severity $(-37<\mathrm{S}<-5)$ near the contact region $(0.9<\mathrm{y}<1.0 /$ Fig. $6 \mathrm{~b})$. From these observations, different potential failure types can be derived:

1) At the contact, the tensile stress concentrations (Fig 6b) may initiate a tensile fracture beneath the contact. The arising fractures propagate along a meridional plane through the sphere and strikes in the centre. Because the stress distribution is rotationally symmetric, a sphere can fail in fragments shaped like orange slices. This tensile cleavage crack is illustrated in figure $6 c$.

2) In the direct vicinity of the contact region, a so-called cone crack may be observed. This cone crack is initiated at a ring crack at the surface, where the tensile stress perpendicular to the contact circle shows a maximum. These ring cracks are known from indenter experiments (Geandier et al., 2003, Warren, 1995). The driving force of this ring crack is the very high Hertzian tensile stress at the surface (Hertz, 1882, Timoshenko and Goodier, 1970). The ring crack propagates only a little into the sphere. Then, the cone crack starts from the contact circle and propagates towards the axis of loading. This leads to a shallow fragment below the contact area (Fig. 6c). From high stress energy density in that area, a dense crack pattern and a large amount of fine fragments may be produced. In addition, the very high compressive stress in the contact region causes an explosive breakage. Fine fragments arise from dense crack pattern affected by high stress energy.

The described failure scenario can be found in the proppant pack (Fig. 6d and 6e). The proppant in figure $6 \mathrm{~d}$ is cleaved into six "orange slices" and the inner part shows the cone crack which is highly fragmented. The micrograph of a proppant loaded between two others (Fig. 6e) identifies two fractures that are initiated at the 
contact region and propagated towards the centre. In addition, chipping of fragments at the proppant surface is observed. The observed crack pattern correlates with the failure types described from theoretical considerations illustrated in figure $6 \mathrm{c}$.

The stress distribution along the loading axis of a sphere for contact angles of $5^{\circ}$ and $1^{\circ}$ is given in figure $6 f$, expressed as the stress severity. Up to a fraction of about 0.7 of the radius $\mathrm{R}$, the stress distribution within the sphere is almost uniform. However, for a small contact angles $\left(\Theta=1^{\circ}\right)$, a high degree of stress anisotropy exists with a severity up to $\sim-40$ at $\mathrm{r} / \mathrm{R} \sim 0.95$, where $\mathrm{r}$ is position. With increasing contact angle $\left(\Theta=5^{\circ}\right)$, the stress concentration decreases (severity of -1.67 at $r / R=0.8$ ) and the extremum is shifted towards the centre (Fig. $6 f$ ). For a small contact angle, the high tensile stress concentrations may initiate a fracture that propagates through the centre of the sphere. In contrast, a larger contact angle reduces this tensile stress concentration. That means a disproportionately high reduction of tensile stresses in loaded sphere is achieved by increasing the contact angle. Hence, the contact angle has a major impact on the stability of a rock grain or a proppant, respectively.

\section{Stress Calculation: Diametral Load of Proppants and Quartz Grains}

The point where the crack growth initiates probably coincides with the maximum induced tensile stress, if microcracks are evenly distributed. Consequently, the theory of Hiramatsu and Oka (1966) is employed to define the maximum tensile stresses in a rock-proppant system. With this approach the early onset of quartz grain crushing at the rock-proppant and the crushing of ISP at high differential stresses may be explained (see Fig. 4). For that purpose, a dual-fit algorithm is used to approximate the maximum tensile stress severity $\left(\mathrm{S}_{\mathrm{t} \_ \text {max }}\right)$ as a function of contact angle $\Theta$ and Poisson ratio $v$ of the material.

$$
\mathrm{S}_{\mathrm{t}_{-} \max }=\left(682 \cdot v^{2}-583 \cdot v+128\right) \Theta^{\left(9.22 \cdot v^{2}-1.33 \cdot v-1.89\right)} \forall 1^{\circ} \leq \Theta \leq 10^{\circ}
$$

$\mathrm{S}_{\mathrm{t} \_\max }$ increases with decreasing $v$ and decreasing $\Theta$. For large $\Theta, \mathrm{S}_{\mathrm{t} \_ \text {max }}$ converge against $\sim-0.6$. The overall error of this approximation is about $11 \%$. The entire derivation of this approximation is given in Reinicke (2010).

The maximum tensile stresses for proppant-proppant contacts (PP contact) and quartz-proppant contacts (QP contact $)$ are computed for four loading steps $\left(\sigma_{\text {diff }}=5,20,35,50 \mathrm{MPa}\right)$, comparable to the experiments presented in the previous section. The contact radii at the defined loading steps are calculated with the Hertzian contact theory (Hertz, 1882, Timoshenko and Goodier, 1970). For the present problem it is assumed that disintegration of spheres will occur in form of tensile splitting along the axis of compression if the stress overcomes tensile strength. The parameters for this calculation are listed in table 2. The load F on a PP contact as well as on the QP contact as a function of the externally applied differential stress $\left(\sigma_{\mathrm{diff}}\right)$ is: 


$$
\mathrm{F}_{\mathrm{PP}}=\mathrm{F}_{\mathrm{QP}}=\frac{\sigma_{\text {diff }} \mathrm{A}_{\mathrm{S}}}{\mathrm{N}_{\mathrm{PL}}}
$$

where $A_{S}$ is the cross sectional area of the specimen, $N_{P L}$ is the number of proppants per layer within the proppant pack and $\mathrm{F}_{\mathrm{PP}}$ and $\mathrm{F}_{\mathrm{QP}}$ are the forces acting on proppant and quartz grain, respectively. $\mathrm{N}_{\mathrm{PL}}$ is derived by weighting 1000 proppants at first and dividing the weight of the proppant pack by the weight of a single proppant.

The maximum tensile stress at ISP-ISP contacts ranges from $40 \mathrm{MPa}$ to $108 \mathrm{MPa}$ (blue bars / Fig. 7). The tensile strength of pure mullite, which is the main phase, is assumed as strength for ISP type ( 110 MPa) indicated by the blue dashed line. In the last loading stage $\left(\sigma_{\text {diff }}=50 \mathrm{MPa}\right)$ the tensile stress reaches the tensile strength of ISP. The maximum tensile stress in quartz grains at the interface increases from $66-160 \mathrm{MPa}$ (red bars / Fig. 7). The dashed lines in red define the tensile strength of quartz. Already at $\sigma_{\text {diff }}=5 \mathrm{MPa}$ the strength of quartz is exceeded, indicating an onset of quartz grain crushing at small external stress.

\section{Stress Calculation: Idealized 2D Contact Model of Quartz Grains and Proppants}

The aim of this pure mechanical elastic modeling approach with an open source finite element (FE) software package (Wang et al., 2009) is the identification of stress patterns that explain the observed fracture pattern in the proppant pack. In order to rebuild the grain structure as well as the shape of proppants precisely, micrographs from Bentheim sandstone and ISP are used to design an idealized 2D contact model. The number of contacts and contact radii is arranged for each proppant or quartz grain. For this modeling approach the contacts between proppants and fracture faces are projected from 3D to 2D. Different contact geometries comparable to possible contact scenarios in a propped fracture are assembled. An embedded proppant (A), a three point load geometry (B \& C), a very small contact area between quartz grains and proppants (B \& C) as well as a very small contact area between proppants $(\mathrm{C} \& \mathrm{E})$ are given in figure 8a. A special procedure is conducted in order to generate a FE-mesh from a micrograph. First step is the conversion from a redgreenblue (rgb) picture into a binary image. The boarders of grains and proppants are smoothed in this binary picture and the geometry is vectorized. An open source mesh generator (Geuzaine and Remacle, 2006) is used to create the finite element mesh. Lines of refinement and different materials (quartz grain and proppant) are defined with the meshing tool. The mesh is fixed and not deformable. Four lines at the outer boundary apply the external stress to the model borders (first order boundary condition). A constant stress $\left(\sigma_{\mathrm{Xx}}\right)$ of $10 \mathrm{MPa}$ is applied to the vertical model boarders. At the horizontal model boarders a vertical stress $\left(\sigma_{\mathrm{YY}}\right)$ of $60 \mathrm{MPa}$ is applied. The mechanical properties of the two materials in contact are taken in accordance to the analytical study (Tab. 2). The dimensions of the investigated 
area are $2.40 \times 3.42 \mathrm{~mm}^{2}$. The output parameter is the minimum principle stress $\sigma_{2}$.

Figure 8a displays the minimum principle stress distribution. Figure $8 \mathrm{~b}$ shows a micrograph of a proppant filled fracture after loading it up to $\sigma_{\text {diff }}=50 \mathrm{MPa}$. In the following, the fracture patterns observed in the micrograph will be compared with the stress patterns of the model. The correlating stress and fracture pattern are denoted with the same number: 1) Highly localized tensile stresses up to $40 \mathrm{MPa}$ are observed at proppant proppant contacts. These tensile stresses can affect a proppant cleavage fracture. The micrograph shows such cleavage fractures in proppants.

2) The numerical calculation identifies high tensile stresses which are mainly horizontally distributed and tend from the contact towards the surface. These stresses with maximum values up to $90 \mathrm{MPa}$ explains the chipping of proppant fragments shown in figure $8 \mathrm{~b}$. This distinct explanation for chipping is not found from the analytical approach. 3) Curved fractures between contacts following the stress trajectories are observed. 4) Total disintegration of quartz grains at the rock-proppant interface creates a lot of fines. The model shows localized tensile stress maxima $\left(\sigma_{2} \leq 40 \mathrm{MPa}\right)$ in the quartz grains (region $\alpha$ and $\beta$ ).

Proppant B illustrates an embedded proppant. Only compressive stresses occur at this rock-proppant contact. This proppant is well supported and initiation of proppant fracturing at the interface is unlikely. This observation is supported by the micrograph. Beside the stress distribution at the rock-proppant interface, it is obvious that in distance of approximately one quartz grain radius, large tensile stresses around the pores arise.

\section{Correlations between Results from Laboratory Experiments and Modeling Approaches}

Measurements conducted with the BDFC highlight that both proppant types create a clear reduction of permeability at the fracture face due to crack damage of rock grains (Fig. 5b and 5d). Already at small differential stresses a significant reduction of permeability for both rock and proppant types is observed. The reduction ratio $\left(\mathrm{k}_{\mathrm{i}} / \mathrm{k}_{\mathrm{S}}\right)$ are in the range of $4-11$, i.e. the permeability at the fracture face is reduced by $75 \%$ 90\%; HSP has a slightly higher damage potential (Fig. 9).

Already the isostatic loading stage $\left(\sigma_{3}: 0-10 \mathrm{MPa}, \sigma_{\text {diff: }} 0 \mathrm{MPa}\right)$ leads to a clear permeability reduction and a high AE activity at the interface (Fig. 4a). With further loading the ongoing permeability reduction is smaller. It is assumed that initially produced fines block the pores at the interface whereas further loading results in a denser crack network but influence the permeability only minor.

The analytical modeling approach highlights that already at small differential stress $\left(\sigma_{\text {diff }}=5 \mathrm{MPa}\right)$ the tensile strength of quartz is exceeded. Hence, we may expect an early onset of quartz grain crushing at the rock- 
proppant interface. This consideration is in good correlation with the AE investigation. The AE activity at the fracture face results from embedment of proppants into the rock matrix and a resulting destruction of rock grains. The produced fines are blocking the pores at the fracture face and result in a permeability reduction of the rockproppant system and a mechanically induced FFS. The high amount of C-type events (compaction events) reflects the compaction of the pore space. At the last loading step $\left(\sigma_{\text {diff }}=50 \mathrm{MPa}\right)$ high AE activity from the proppant pack is observed. The analytical calculation at ISP-ISP contacts results in tensile stresses up to 108 MPa (Fig. 7, blue bars) and reaches the tensile strength of this material. Hence, the failure of proppants within the proppant pack may be expected at maximum differential stress which is in good correlation the observed $\mathrm{AE}$ pattern (Fig. 4e). Additionally, the analytical calculation predicts failure in tensile mode and with increasing load (onset of proppant failure) an increase of T-type events is observed (Fig. 4c-e).

The numerical finite element model of the rock-proppant interface delivers stress patterns that are in good correlation with observed fracture patterns. But, the calculated tensile stresses are too small to explain neither proppant nor quartz crushing. The maxima of tensile stress are highly localized along the axis of loading. The used mesh spacing might be too large to detect the high tensile stress concentrations.

In a distance of approximately one quartz grain radius, large tensile stresses around the pores arises (Fig. 8a). The $\mathrm{AE}$ investigation detects a zone of $\mathrm{AE}$ activity at the rock proppant interface of $\sim 4 \mathrm{~mm}$. This accords to 12 quartz grain radii approximately. Hence, some amount of the recorded activity might be attributed to grain deformation and crushing along the grain-pore and grain-grain boundaries. Blöcher et al. (2007) simulated the pore structure deformation of Bentheim sandstone with the mentioned FE software package in a hydrostatic compression experiment up to $70 \mathrm{MPa}$ effective stress. They found high tensile stresses near grain contacts and neighboring pores $(\sim 100 \mathrm{MPa})$ as well. Grain crushing may be expected in some distance from the rockproppant contact. But the investigated area is too small to differentiate between near field and far field effects of stresses induced at the rock-proppant interface. A continuative study including a rock layer larger than 12 grain radii is necessary to clarify if these high stresses are caused by the point loading from rock-proppant interface.

Schönert (2004) stated that the explosive fracturing type of spheres that creates a high amount on fines could be suppressed if the sphere is plastically deformed at the contact face. This inelastic deformation increases the contact area and decreases the stress density as well as the stress severity in the sphere dramatically. A resin coating provides exactly the function of an inelastic deformable material and stabilizes therefore the proppant and attenuates embedment effects. Additionally, the larger contact area will suppress the explosive fracturing and will advance a cleavage into "bigger" orange slices. Fines production and proppant embedment can be 
reduced with resin coated proppants.

\section{Influence on Well Productivity}

Measurements conducted with the Bidirectional Flow Cell highlights that both proppant types create a clear reduction of permeability at the fracture face due to mechanical interactions of proppant and rock. The ratio of permeability reduction for maximum $\sigma_{\text {diff }}$ varies between 4 and 11 depending on proppant and rock type. The influence of permeability reduction on dimensionless productivity index $\mathrm{PI}_{\mathrm{D}}$ is computed for the pseudo steady state flow regime. For this purpose the FFS value is calculated (Cinco-Ley and Samaniego-V., 1977):

$$
\mathrm{FFS}=\frac{\pi \cdot \mathrm{w}_{\mathrm{s}}}{\mathrm{x}_{\mathrm{f}}}\left(\frac{\mathrm{k}_{\mathrm{i}}}{\mathrm{k}_{\mathrm{s}}}-1\right)
$$

and the $\mathrm{PI}_{\mathrm{D}}$ is determined from Romero et al. (2003):

$$
\mathrm{PI}_{\mathrm{D}}=\frac{1}{\frac{1}{\mathrm{PI}_{\mathrm{D}, \mathrm{FFS}=0}}+\mathrm{FFS}}
$$

with $\mathrm{PI}_{\mathrm{D}, \mathrm{FFS}=0}$ representing the dimensionless productivity index of the well with zero fracture face skin. The calculation is conducted for a fracture half length $\mathrm{x}_{\mathrm{f}}=60 \mathrm{~m}$; this length corresponds with the fracture half length created during hydraulic stimulation in the geothermal research well Gross Schoenbeck, Germany (Zimmermann and Reinicke, 2010).

This calculation leads to a reduction of the long term productivity of $0.1-0.2 \%$ (Tab. 3 ). This small reduction indicates that other influences on the permeability of fracture face and proppant pack may lead to productivity reduction considerably higher (up to $90 \%$ ); effects like fluid-loss damage (Cinco-Ley and Samamiego-V., 1981), filter cake build-up at the fracture face (Romero et al., 2003), or water blockage due to relative permeability changes (Holditch, 1979). This calculation makes clear that the direct influence of the mechanical induced fracture face skin is negligible compared to the listed productivity damage mechanisms.

However, secondary effects may be triggered due to the presence of a zone with reduced porosity at the fracture face. The reduced pore space may act as filter leading to an internal filtering of migrating fines in the reservoir fluid during production. Static internal filtration experiments with Bentheim sandstone have shown that a suspension containing particles with a pore throat radius to particle radius ratio of 12.5 lead to considerable permeability reduction of $90 \%$ (Al-Abduwani et al., 2003). Modeling of filter clogging affected by a suspension indicates that a ratio of 200 between effective pore size and suspension particle diameter is sufficient to clog a filter effectively (Azarov et al., 2007). These studies highlight the impact of a reduced porosity at the fracture 
face. The deposit of fines transported from the reservoir rock to the fracture can cause a long term impairment of a reservoir. This is certainly a hypothesis and may be investigated in further laboratory experiments as well as numerical studies.

\section{Conclusions}

The rock-proppant interaction experiments with the AEFC point out that grain crushing, proppant embedment, and fines production start at low differential stresses $(\sim 5 \mathrm{MPa})$ at the fracture face. With increasing differential stress $(>20 \mathrm{MPa})$, the AE activity shifts into the proppant pack indicating increasing proppant failure. The analytical stress modeling identified high tensile stress concentrations in the rock-proppant system responsible for early onset of acoustic emission, quartz grain crushing at low external stress and proppant failure at high external stress. The disintegration of quartz grains starts at small differential stresses and result in fines production and blocking of pores at the fracture face. This leads to a mechanically induced fracture face skin (FFS) with a reduction of permeability at the fracture face up to a factor of eleven. The material properties of proppants (ISP or HSP) have only a small influence on the permeability reduction at the fracture face; the HSP have a slightly higher damage potential.

Beside the tensile stress driven cleavage of proppants, the high compressive stress energy can affect an explosive type of fracturing and a high amount of fines. The explosive type of fracturing as well as the embedment of proppants can be suppressed if the sphere is plastically deformed at the contact face. A resin coating provides the function of a plastically deformable material. The numerical FE modeling of the rock-proppant system identified stress patterns which are in good correlation with fracture patterns observed from micrographs of the rockproppant interaction experiments. Proppant disintegration is initiated at proppant-proppant contacts at high differential stresses.

The direct effect of the mechanically induced FFS on the well productivity at field conditions is expected to be negligible. In comparison, effects like fluid-loss into the fracture face, filter cake build-up at the fracture face or relative permeability changes may generate a significantly larger FFS. However, secondary effects like internal filtering may significantly reduce the reservoir productivity during production.

The present study highlights the importance of an improved understanding of rock-proppant systems under insitu conditions in order to supplement field experience and define a best practice strategy for hydraulic proppant fracturing. 


\section{Acknowledgements}

I like to extend my thanks to the reviewers for their very valuable input. T. Backers as well as GeoMecon $\mathrm{GmbH}$, Germany is acknowledged for supporting this work. I extend thanks to W. von Stillfried (TU Berlin, Germany) for his contributions to FE modeling work, to D. Naumov (TU Berlin, Germany) for his support during analytical stress calculation, and to S. Gehrmann (GFZ German Research Centre for Geoscience) for preparation of samples and thin sections. This work was funded by the Helmholtz Centre Potsdam GFZ German Research Centre for Geosciences and the Federal Ministry for Environment, Nature Conservation and Nuclear Safety. 
Nomenclature

\begin{tabular}{|l|l|l|}
\hline symbol & unit & description \\
\hline$\Delta \mathrm{P}_{\mathrm{P}}$ & {$[\mathrm{MPa}]$} & differential pore pressure \\
\hline$v$ & {$[1]$} & Poisson ratio / Poisson number \\
\hline$\eta$ & {$[\mathrm{Pa} \mathrm{s}]$} & dynamic fluid viscosity \\
\hline$\sigma_{1}, \sigma_{2}, \sigma_{3}$ & {$[\mathrm{MPa}]$} & principle stress \\
\hline$\sigma_{\mathrm{diff}}$ & {$[\mathrm{MPa}]$} & differential stress \\
\hline$\Theta$ & {$\left[{ }^{\circ}\right]$} & contact angle \\
\hline & & \\
\hline $\mathrm{A}$ & {$\left[\mathrm{m}^{2}\right]$} & area \\
\hline $\mathrm{F}$ & {$[\mathrm{N}]$} & force \\
\hline $\mathrm{F}_{\mathrm{PP}} / \mathrm{F}_{\mathrm{QP}}$ & {$[\mathrm{N}]$} & force at: proppant-proppant / quartz-proppant contact \\
\hline $\mathrm{FFS}$ & {$[1]$} & fracture face skin \\
\hline $\mathrm{k}$ & {$\left[\mathrm{m}^{2}\right]$} & permeability \\
\hline $\mathrm{k}_{\mathrm{i}} / \mathrm{k}_{\mathrm{f}} / \mathrm{k}_{\mathrm{S}} / \mathrm{k}_{\mathrm{T}}$ & {$\left[\mathrm{m}^{2}\right]$} & $\begin{array}{l}\text { initial rock permeability / fracture permeability / permeability of fracture face skin } \\
\text { zone / total permeability of rock-proppant system }\end{array}$ \\
\hline $\mathrm{L}_{\mathrm{i}} / \mathrm{L}_{\mathrm{T}}$ & {$[\mathrm{m}]$} & length of intact rock sample / total length of rock-proppant system \\
\hline $\mathrm{N}_{\mathrm{PL}}$ & {$[1]$} & number of proppants per layer \\
\hline $\mathrm{PI}$ & {$[1]$} & dimensionless productivity index \\
\hline $\mathbf{Q}$ & {$\left[\mathrm{m}^{3} / \mathrm{s}\right]$} & flow rate \\
\hline $\mathrm{S} / \mathrm{S}_{\mathrm{t} m a x}$ & {$[1]$} & stress severity / maximum tensile stress severity \\
\hline $\mathrm{W}_{\mathrm{f}} / \mathrm{w}_{\mathrm{S}}$ & {$[\mathrm{m}]$} & fracture width / extent of fracture face skin zone (damage penetration) \\
\hline \multicolumn{2}{|l}{} \\
\hline
\end{tabular}

\section{SI Units Conversion Section}

\begin{tabular}{|l|l|l|l|}
\hline parameter & unit & conversion factor & SI unit \\
\hline dynamic fluid viscosity & {$[\mathrm{Pa} \mathrm{s}]$} & 1 & {$[\mathrm{~kg} / \mathrm{s} / \mathrm{m}]$} \\
\hline flow rate & {$[\mathrm{ml} / \mathrm{min}]$} & $6 \mathrm{E}-7$ & {$\left[\mathrm{~m}^{3} / \mathrm{s}\right]$} \\
\hline force & {$[\mathrm{N}]$} & 1 & {$\left[\mathrm{~kg} \cdot \mathrm{m} / \mathrm{s}^{2}\right]$} \\
\hline permeability & {$[\mathrm{D}]$} & $0.9869 \cdot \mathrm{E}-12$ & {$\left[\mathrm{~m}^{2}\right]$} \\
\hline pore pressure & {$[\mathrm{bar}]$} & $1 \mathrm{E} 5$ & {$\left[\mathrm{~kg} / \mathrm{s}^{2} / \mathrm{m}\right]$} \\
\hline stiffness & {$[\mathrm{N} / \mathrm{m}]$} & 1 & {$\left[\mathrm{~kg} / \mathrm{s}^{2}\right]$} \\
\hline stress / Young's modulus & {$[\mathrm{Pa}]$} & 1 & {$\left[\mathrm{~kg} / \mathrm{s}^{2} / \mathrm{m}\right]$} \\
\hline
\end{tabular}




\section{References}

Al-Abduwani, F.A.H.; Shirzadi, A.; van den Broek, W.M.G.T., and Currie, P.K. "Formation Damage vs. Solid Particles Deposition Profile during Laboratory Simulated PWRI” SPE 82235, (2003)

Anderson, R.W.; Cooke, C.E., and Wendorff, C.L "Propping Agents and Fracture Conductivity in Recent Advances in Hydraulic Fracturing” SPE Monograph Series, Vol. 12, (1989)

Azarov, A., Radkowski D., and Baron, R. "Modeling of Filter Clogging During Suspension Filtering" Proceedings, COMSOL Conference 2007, Boston, USA, (2007)

Behr, A., Mtchedlishvili, G., Friedel, T., and Haefner, F. “Consideration of Damage Zone in Tight Gas Reservoir Model with Hydraulically Fractured Well” SPE 82298, (2002)

Blöcher, G., Bruhn, D.; Zimmermann, G.; McDermott, C., and Huenges, E. „Investigation of the undrained poroelastic response of sandstones to confining pressure via laboratory experiment, numerical simulation and analytical calculation, Rock physics and geomechanics in the study of reservoirs and repositories" The Geological Society, (2007)

Cinco-Ley, H. and Samaniego-V., F. "Effect of Wellbore Storage and Damage on the Transient Pressure Behaviour of Vertically Fractured Wells" SPE 6752, (1977)

Cinco-Ley, H. and Samaniego-V., F. "Transient pressure analysis: Finite conductivity Fracture case versus damaged fracture case” SPE 10179, (1981)

Cramer, D.D. "Fracture Skin: A Primary Cause of Stimulation Ineffectiveness in Gas Wells” SPE 96869, (2005)

Darcy, H. "Les fontaines publiques de la ville de Dijon" Dalmont, Paris., The famous Appendix - Note D appears here.:647 \& atlas, (1856)

Economides, M.J. and Nolte, K.G. "Reservoir Stimulation" $3^{\text {rd }}$ Edition, Wiley and Sons Ltd., United Kingdom, (2000)

Fredd, C.N., McConnell, S.B., Boney, C.L., and England, K.W. "Experimental Study of Hydraulic Fracture Conductivity Demonstrates the Benefits of Using Proppants” SPE 60326, (2000)

Geandier G., Denis, S., and Mocellin, A. "Float glass fracture toughness determination by Hertzian contact: experiments and analysis” Journal of Non-Crystalline Solids 318, (2003)

Geuzaine, C. and Remacle, J. F. "Gmsh: a threedimensional finite element mesh generator with built-in pre- and post-processing facilities" Case Western Reserve University, Cleveland, OH, (2006) 
Hertz, H. „Ueber die Beruehrung fester elastischer Koerper“ J. Reine und Angewandte Mathematik 92, 156, (1882)

Hiramatsu, Y. and Oka, Y. "Determination of the tensile strength of rock by a compression test of an irregular test piece” Int. J. Rock Mech. Min. Sci, 3, (1966)

Hoek, E. and Franklin, J. A. "Simple triaxial cell for field or laboratory testing of rock” Trans. Inst. Min. Metall, 77:A22 (Section A), (1968)

Holditch, S.A. "Factors Affecting Water Blocking and Gas Flow from Hydraulically Fractured Gas Wells" JPT, $1515-1524,(1979)$

Klein, E. and Reuschlé, T. „A model for the mechanical behaviour of Bentheim Sandstone in the Brittle Regime” Pure and Appl. Geophys, 160, (2003)

Legarth, B., Raab, S, and Huenges, E. "Mechanical Interactions between proppants and rock and their effect on hydraulic fracture performance” DGMK-Tagungsbericht 2005-1, Fachbereich Aufsuchung und Gewinnung, (2005)

Lynn, J.D., Hisham, A., and Nasr-El-Din, H.A. "Evaluation of formation damage due to frac stimulation of a Saudi Arabian clastic reservoir" J. of Petr. Sc.and Eng. 21, (1998)

Moghadasi, J; Jamialahmadi, M.; Müller-Steinhagen, H.; Sharif, A., and Izadpanah, M. R. „Formation Damage in Iranian Oil Fields” SPE 73781, (2002)

Nasr-El-Din, H.A. "New Mechanisms of Formation Damage: Lab Studies and Case Histories” SPE 82253, (2003)

Reinicke, A. "Mechanical and Hydraulic Aspects of Rock-Proppant Systems_Laboratory Experiments and Modelling Approaches” Doctoral Thesis. Universität Potsdam, Germany, (2010)

Romero, D.J.; Valkó, P.P., and Economides, M.J. "Optimization of the Productivity Index and the Fracture Geometry of a Stimulated Well With Fracture Face and Choke Skins”SPE 81908, (2003)

Schönert, K. "Breakage of spheres and circular discs" Institute of Mineral Processing, Powder Technology 143$144,(2004)$

Shackelford, J.F. (Ed.) and Alexander, W. (Ed.) “The CRC Materials Science and Engineering Handbook” CRC Press, (2000) 
Timoshenko S. P. and Goodier, J. N. "Theory of elasticity“ $3^{\text {rd }}$ Edition, McGrawHill, Kogakusha, Tokyo, (1970)

Trautwein, U. „Poroelastische Verformung und petrophysikalische Eigenschaften von Rotliegend Sandsteinen” doctorial thesis, Technischen Universität, Berlin, (2005)

Wang, H.F. "Theory of linear poroelasticity with applications to geomechanics and hydrogeology" Princeton University Press, Princeton, NJ., (2000)

Wang,W., Kosakowski, G., and Kolditz, O. “A parallel finite element scheme for thermo-hydro-mechanical (THM) coupled problems in porous media” Computers \&Geosciences 35, (2009)

Warren, P. D. "Determining the Fracture Toughness of Brittle Materials by Hertzian Indentation” Journal of the European Ceramic Society 15, (1995)

Wen, Q., Zhang, S., Wang, L., Liu, Y., and Li, X. „The effect of proppant embedment upon the long-term conductivity of fractures" Journal of Petroleum Science and Engineering 55, (2006)

Zang, A., Wagner, F.C., Stanchits, S., Dresen, G., Andresen, R., and Haidekker, M.A. "Source analysis of acoustic emissions in Aue granite cores under symmetric and asymmetric compressive loads" Geophys., J. Int., 135, (1998)

Zimmermann, G. and Reinicke, A. "Hydraulic stimulation of a deep sandstone reservoir to develop an Enhanced Geothermal System: Laboratory and field experiments” Geothermics, 39, 1, (2010) 


\begin{tabular}{|c|c|c|c|c|c|c|}
\hline & AEFC & & & DFC & & \\
\hline experiment & no. 1 & no. 2 & no. 3 & no. 4 & no. 5 & unit \\
\hline rock type & Bentheim ss & Bentheim ss & Bentheim ss & Flechtingen ss & Flechtingen ss & \\
\hline specimen length & 125.2 & 64.0 & 65.2 & 65.3 & 63.3 & $\mathrm{~mm}$ \\
\hline specimen diameter & 50 & 50 & 50 & 50 & 50 & $\mathrm{~mm}$ \\
\hline initial fracture width & 5.16 & 4.6 & 3.9 & 4.8 & 3.9 & $\mathrm{~mm}$ \\
\hline conf. pressure & 10 & 10 & 10 & 10 & 10 & $\mathrm{MPa}$ \\
\hline diff. stress & $0-51$ & $0-52$ & $0-52$ & $0-50$ & $0-50$ & $\mathrm{MPa}$ \\
\hline strain rate & $8.010^{-6}$ & $1.610^{-6}$ & $1.610^{-6}$ & $1.610^{-6}$ & $1.610^{-6}$ & $\mathrm{~s}^{-1}$ \\
\hline flow rate & 5 & 5 & 5 & 0.05 & 0.05 & $\mathrm{ml} / \mathrm{min}$ \\
\hline initial permeability & 1630 & 1480 & 1460 & 0.196 & 0.196 & $\mathrm{mD}$ \\
\hline proppants & ISP / 10 & ISP / 10 & $\mathrm{HSP} / 10$ & ISP / 10 & $\mathrm{HSP} / 10$ & $\mathrm{~kg} / \mathrm{m}^{2}$ \\
\hline
\end{tabular}

Table 1: Testing parameters for the rock-proppant interaction experiments using Bentheim and Flechtingen sandstone, with intermediate and high strength proppants (ISP and HSP) 


\begin{tabular}{|c|c|c|c|c|}
\hline & Young's modulus & Poisson ratio & tensile strength & diameter \\
\hline quartz grain & $80 \mathrm{GPa}$ & 0.17 & $\sim 60 \mathrm{MPa}$ & $300 \mu \mathrm{m}$ \\
\hline proppant (mullite) & $160 \mathrm{GPa}$ & 0.23 & $\sim 110 \mathrm{MPa}$ & $760 \mu \mathrm{m}$ \\
\hline
\end{tabular}

Table 2: Mechanical parameters used for analytical stress calculations in quartz grains and proppants (Shackelford and Alexander, 2000) 


\begin{tabular}{|l|c|c|c|c|c|c|}
\hline & Bentheim & & & Flechtingen & & \\
& sandstone & & sandstone & & \\
& max. & \multirow{2}{*}{ FFS } & reduction & max. & FFS & reduction \\
& $\mathrm{k}_{\mathrm{i}} / \mathrm{k}_{\mathrm{S}}$ & & $\mathrm{k}_{\mathrm{i}} / \mathrm{k}_{\mathrm{S}}$ & & [\%] \\
& & & & & & \\
\hline ISP & $10.6 \pm 1.1$ & $2.010^{-3}$ & 0.20 & $7.2 \pm 0.4$ & $9.210^{-4}$ & 0.09 \\
\hline HSP & $11.3 \pm 2.0$ & $2.210^{-3}$ & 0.22 & $7.9 \pm 0.5$ & $1.110^{-3}$ & 0.11 \\
\hline
\end{tabular}

Table 3: Reduction of long term productivity $\mathrm{Pl}_{\mathrm{D}}$ calculated from the measured permeability reduction at the rockproppant interface. 


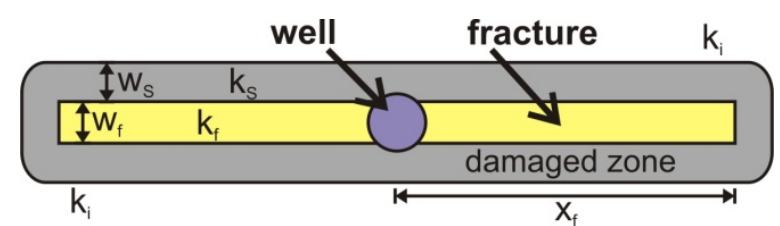

$\begin{array}{ll}k_{i}\left[m^{2}\right] \text { : reservoir permeability } & x_{f}[m] \text { : fracture half length } \\ k_{s}\left[m^{2}\right] \text { : FFS zone permeability } & w_{f}[m] \text { : fracture width } \\ k_{f}\left[m^{2}\right] \text { : fracture permeability } & w_{S}[m] \text { : extent of damaged zone }\end{array}$

Figure 1: Conceptual model of a fracture face skin: Flow impairment (reduced permeability) at the fracture face can affect the productivity of a reservoir. It is commonly referred to as fracture face skin (FFS) (Cinco-Ley and SamaniegoV., 1977). 


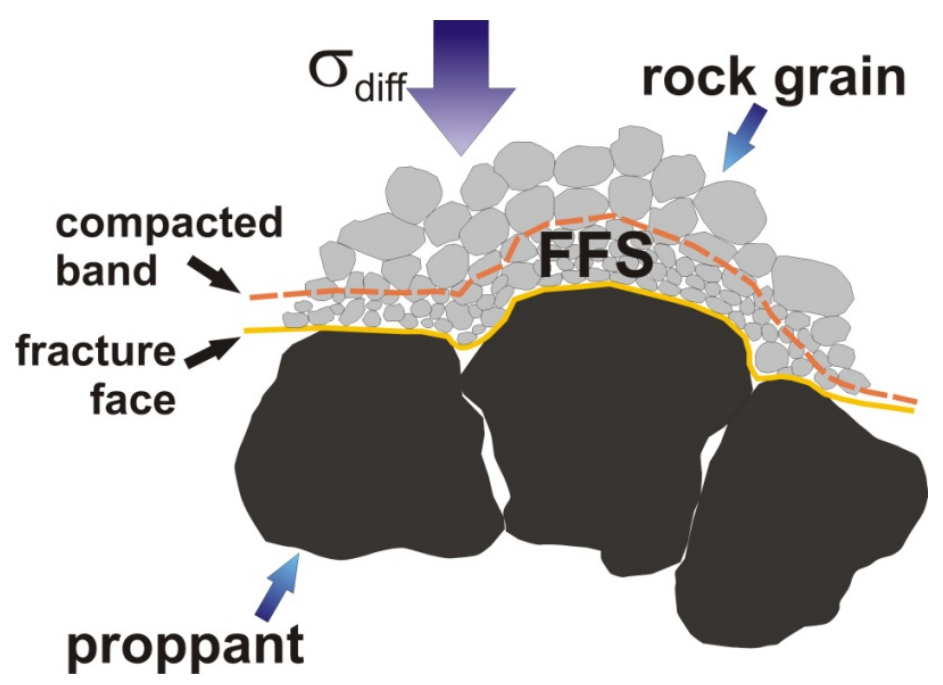

Figure 2: Increasing effective stress on the rock-proppant interface leads to proppant embedment and grain crushing. This causes fines production and a compacted zone. The permeability is reduced in the FFS zone (modified from Legarth et al., 2005). 


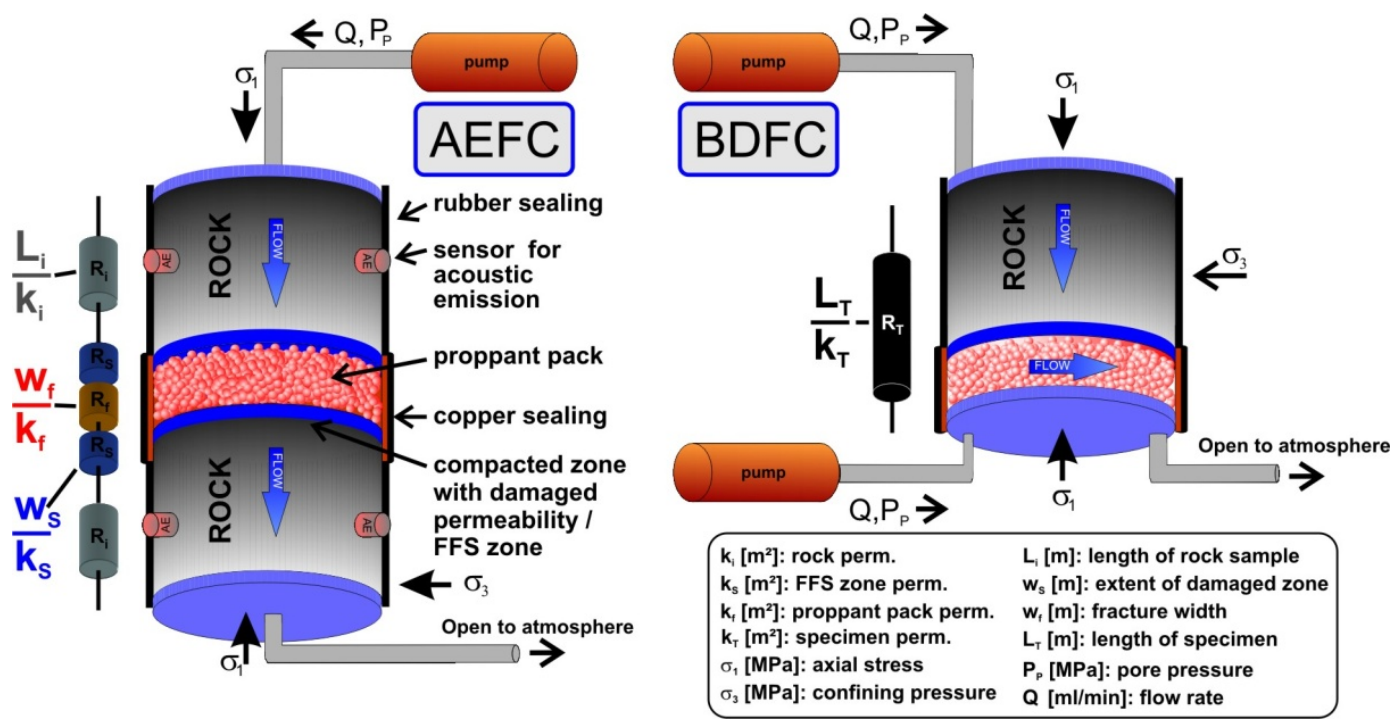

Figure 3: The Acoustic Emission Flow Cell (AEFC) is equipped with piezoelectric $P$ wave transducers in order to identify microfracture processes at the contact of rock and proppant. The BiDirectional Flow Cell (BDFC) provides two flow directions: normal and parallel to the fracture face. The mechanically induced fracture face skin is quantified with this setup. For that purpose, the setup is approximated as a series connection of hydraulic resistors $\left(\mathbf{R}_{\mathrm{T}}=\mathbf{R}_{\mathrm{i}}+\mathbf{R}_{\mathrm{S}}+\mathbf{R}_{\mathrm{f}}\right)$. 


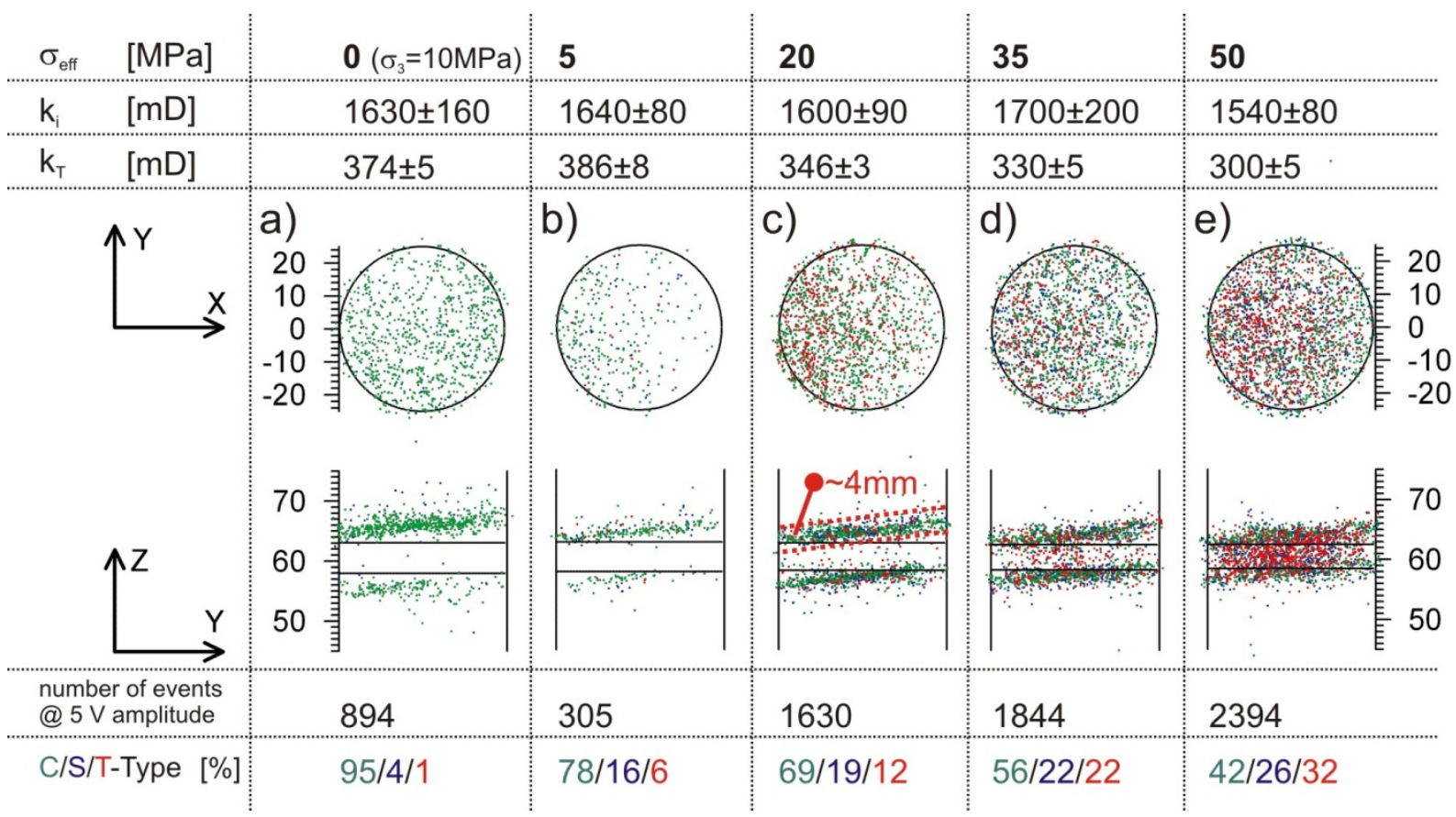

Figure 4: Permeabilities and AE hypocenters for Bentheim sandstone loaded with $2 \mathrm{lb} / \mathrm{ft}^{2}$ of ISP. Initial permeability of this specimen is about $1600 \mathrm{mD}$. The loading up to a $\sigma_{\text {diff }}=50 \mathrm{MPa}$ led to a significant permeability reduction of the rock-proppant system $\left(k_{\mathrm{T}}=300 \mathrm{mD}\right)$. The clustering of $\mathrm{AE}$ hypocenters indicated that grain crushing and proppant embedment started at the fracture faces at small external stresses. With increasing $\sigma_{\text {diff }}$ the AE activity moved into the proppant pack and the proportion of tensile events increased. 

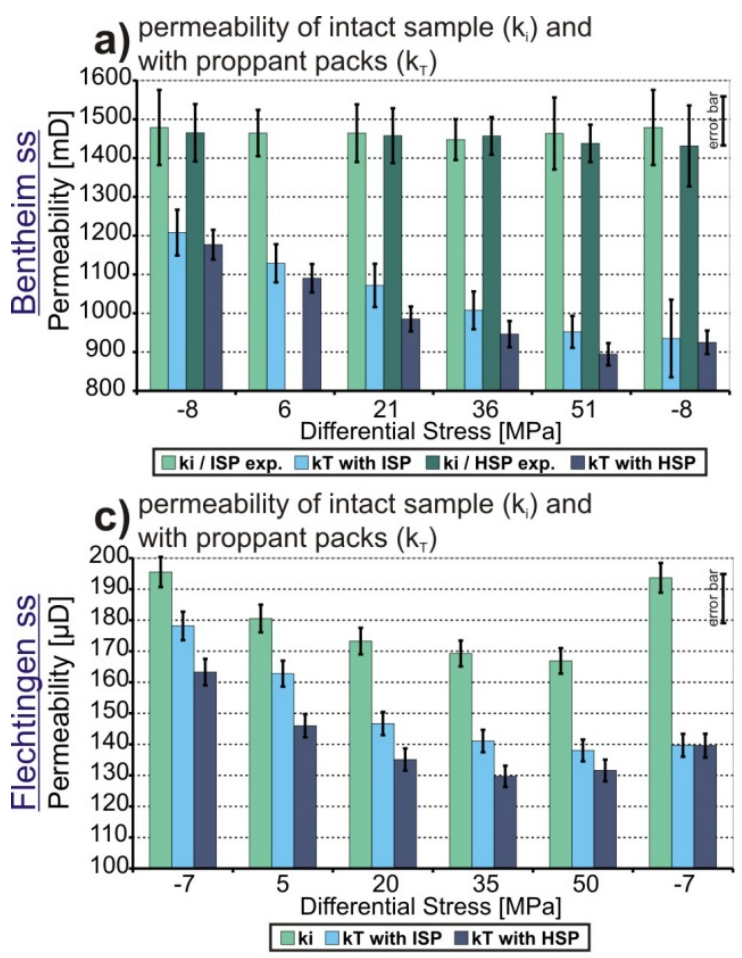

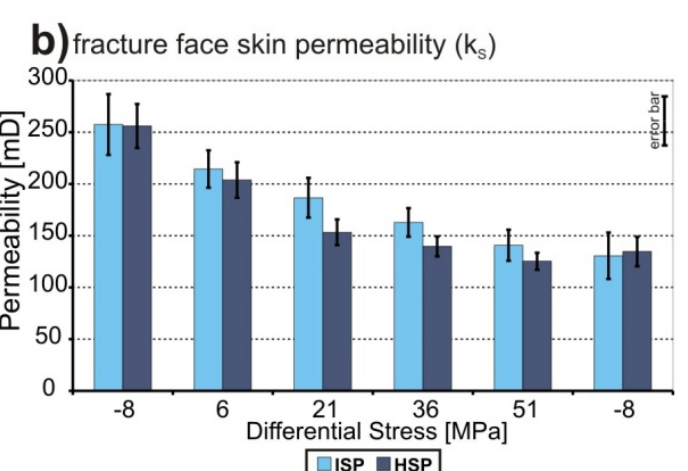

d) fracture face skin permeability $\left(k_{s}\right)$

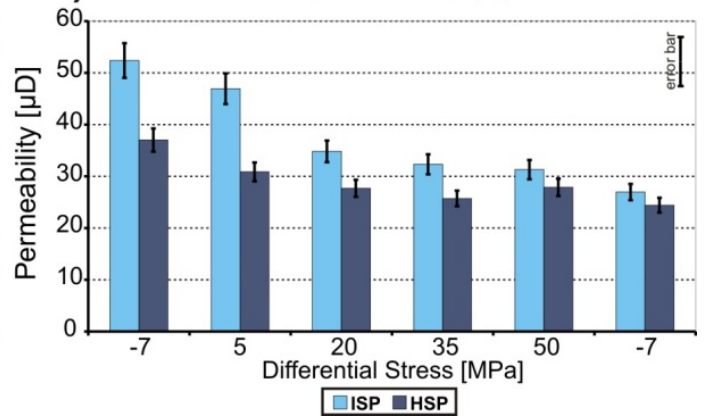

Figure 5: Results from rock-proppant interaction testing of ISP and HSP with Bentheim and Flechtingen sandstone. a) The permeability of Bentheim sandstone was not stress dependent within the applied stress interval, whereas the rockproppant system featured a significant permeability reduction with increasing differential stress. b) This led to a permeability reduction at the fracture face up to $90 \%$ compared to $k_{i}$. c) The permeability of Flechtingen sandstone $\left(k_{i}\right)$ showed a poroelastic permeability reduction of $15 \%$ within the applied stress interval. The rock-proppant system featured a significant higher permeability reduction with increasing differential stress. d) This decrease was caused by the permeability reduction up to $87 \%$ at the rock-proppant interface where the mechanically induced fracture face skin forms. 

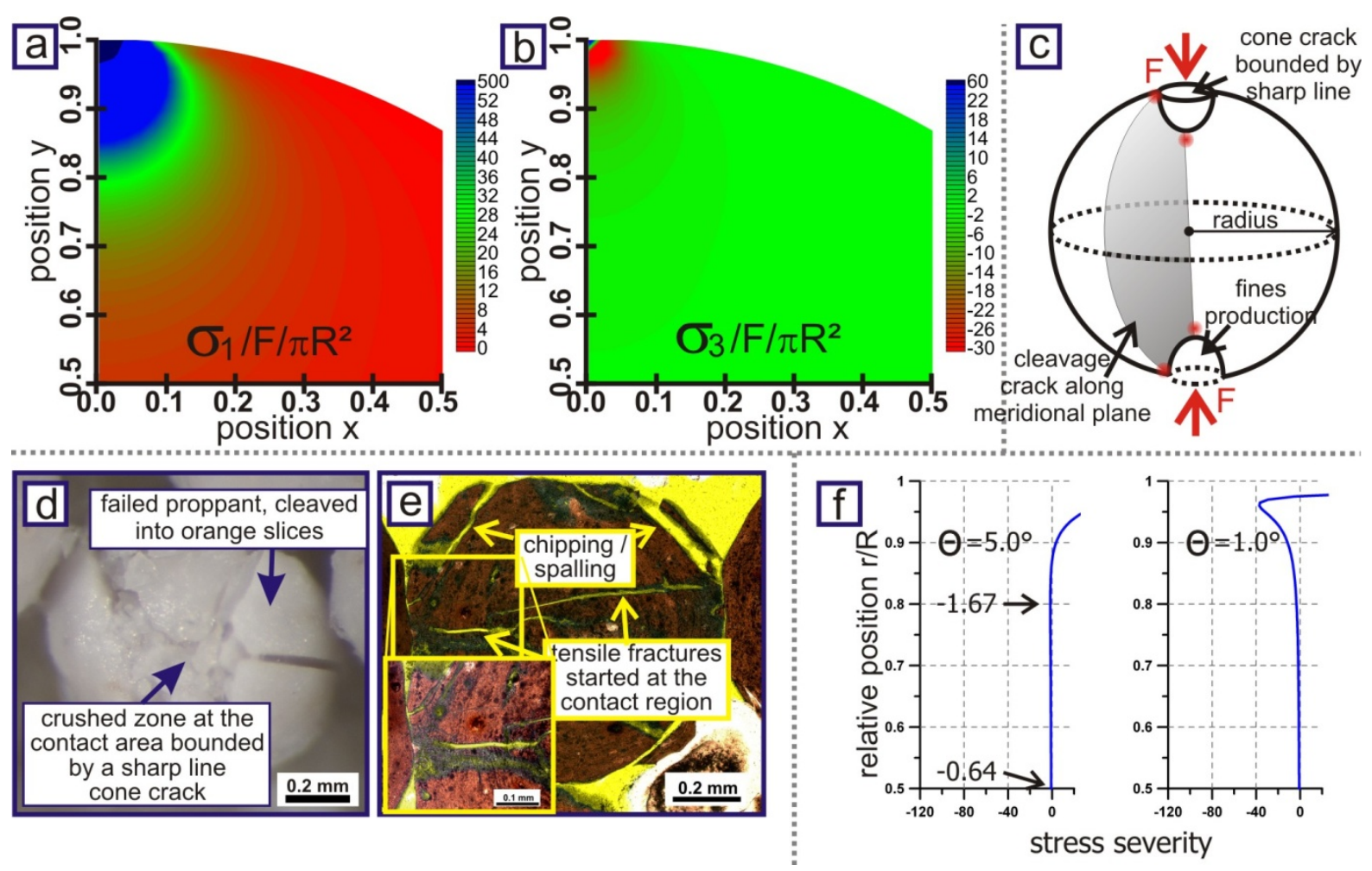

Figure 6: a \& b) Stress severity of principal stresses $\left(\sigma_{1}\right.$ and $\left.\sigma_{3}\right)$. of a diametral loaded sphere. The largest principle stress $\left(\sigma_{1}\right)$ is everywhere compressive; the maximum is about 500 (a / dark blue area). A tensile stress concentration beneath the surface is obvious ( $b$ / red area) c) Possible fracture pattern in a diametral loaded sphere. The stress field in diametral loaded spheres leads to two possible fracture types: the cone crack at the contact and the cleavage crack. The red dots indicate points of fracture initiation. $d \&$ e) Fractures in proppants. A proppant is cleaved into orange slices, and the cone crack area is visible (d). The contact area is highly fragmented, and abundant fines are produced. The tensile stress concentration beneath the contact very likely initiated a fracture that propagates towards the centre (e). f) Stress distribution along axis of loading in spheres (radius R). Decreasing contact angles ( $\Theta$ ) induce strongly increasing tensile stress concentration beneath the surface $(R=1)$. 


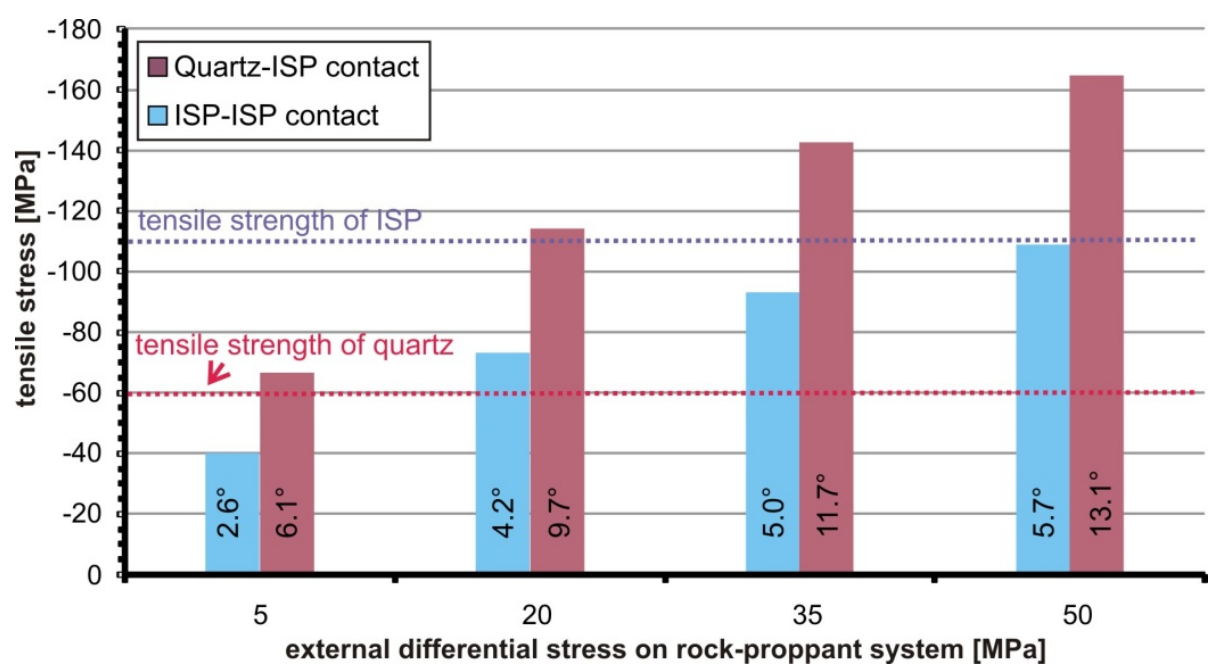

Figure 7: Maximum tensile stresses in quartz grains and proppants as a function of the external differential stress. Already at small external differential stresses $(5 \mathrm{MPa})$ the tensile stress in quartz exceeds the tensile strength of quartz (red line). At maximum differential stress (50 MPa), the tensile stresses at ISP-ISP contacts reach the strength of this proppant type (blue line) and failure of proppants is to be expected. The numbers at the bars express the contact angels. 

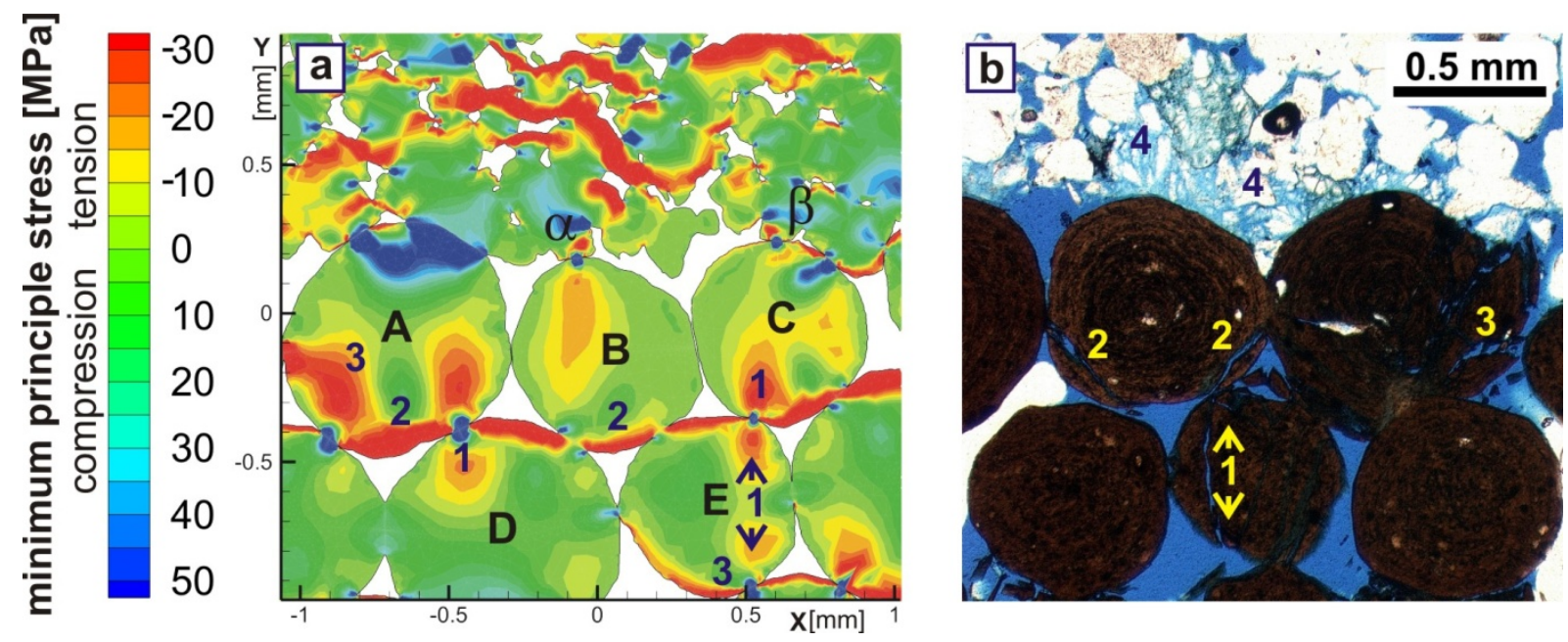

Figure 8: An idealized 2D contact model (a) is created in order to calculate minimum principle stress at the rockproppant interface with an open source finite element (FE) software package (Wang et al., 2009). High tensile stress concentration $(1,2,3, \alpha, \beta)$ are visible at the contacts of proppants and quartz grains. These stress patterns can be correlated with crack pattern observed from a micrograph (b). 1) Cleavage fractures splitting a proppant; 2) Chipping off at the contact of proppants; 3) Curved tensile fractures. 4) The micrograph identifies crushed quartz grains at the rock-proppant interface. The produced fines are blocking the pores and resulting in the mechanically induced fracture face skin. 


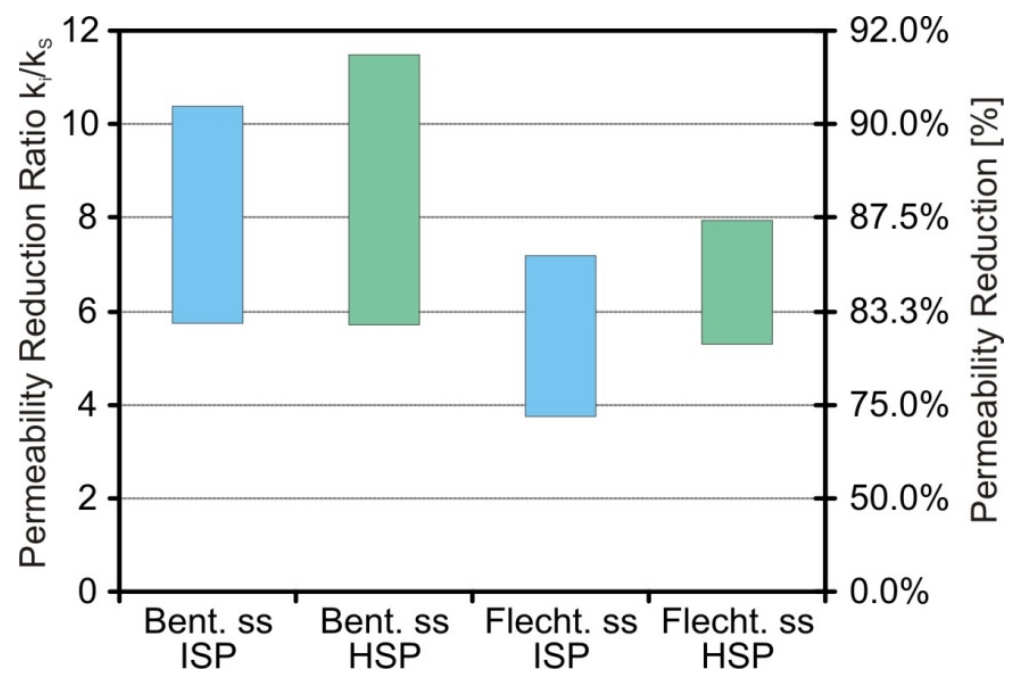

Figure 9: Permeability reduction ratio of different rock-proppant interaction experiments. The reduction ratio of Bentheim sandstone (ss) is about $50 \%$ higher compared to Flechtingen sandstone. Between the two proppant types (ISP and HSP) no clear difference can be ascertained. HSP seems to feature a slightly higher damage potential. 